\title{
Formation mechanism of primary phases and eutectic structures within undercooled $\mathrm{Pb}-\mathrm{Sb}$-Sn ternary alloys
}

\author{
WANG WeiLi, DAI FuPing \& WEI BingBo ${ }^{\dagger}$ \\ Department of Applied Physics, Northwestern Polytechnical University, Xi'an 710072, China
}

The solidification characteristics of three types of $\mathrm{Pb}$-Sb-Sn ternary alloys with different primary phases were studied under substantial undercooling conditions. The experimental results show that primary $(\mathrm{Pb})$ and $\mathrm{SbSn}$ phases grow in the dendritic mode, whereas primary ( $\mathrm{Sb}$ ) phase exhibits faceted growth in the form of polygonal blocks and long strips. $(\mathrm{Pb})$ solid solution phase displays strong affinity with SbSn intermetallic compound so that they produce various morphologies of pseudobinary eutectics, but it can only grow in the divorced eutectic mode together with (Sb) phase. Although (Sb) solid solution phase and SbSn intermetallic compound may grow cooperatively within ternary eutectic microstructures, they seldom form pseudobinary eutectics independently. The $(\mathrm{Pb})+(\mathrm{Sb})+\mathrm{SbSn}$ ternary eutectic structure usually shows lamellar morphology, but appears as anomalous eutectic when its volume fraction becomes small. EDS analyses reveal that all of the three primary $(\mathrm{Pb}),(\mathrm{Sb})$ and $\mathrm{SbSn}$ phases exhibit conspicuous solute trapping effect during rapid solidification, which results in the remarkable extension of solute solubility.

undercooling, dendritic growth, eutectic growth, ternary eutectic, solute trapping

The solidification of eutectic alloys, which involves the competitive nucleation and cooperative growth of two or more eutectic phases from one liquid phase, is an important research subject in the field of material physics. For the binary eutectic growth, there have been sufficient investigations which lay the foundation of successful theoretical models ${ }^{[1]}$. In contrast, the solidification process of ternary eutectic alloys is very complicated ${ }^{[1-12]}$, which requires further profound investigations. Most of the recent research on ternary eutectic solidification pays more attention to the extension of the classic JH model, the evolution of solidification structure, and the properties of ternary alloys under equilibrium or quasi-equilibrium conditions. Himemiya et al. ${ }^{[5]}$ extended JH model to the coupled growth of three phases in ternary eutectic alloys. Souza et al. ${ }^{[6]}$ studied the growth

Received February 11, 2007; accepted May 18, 2007 doi: 10.1007/s11433-007-0046-6

${ }^{\dagger}$ Corresponding author (email: bbwei@nwpu.edu.cn)

Supported by the National Natural Science Foundation of China (Grant Nos. 50121101 and 50395105) 
mechanism of the primary phase and the evolution of eutectic microstructure in Al-Cr-Nb ternary eutectic alloy under directional solidification conditions. Witusiewicz et al. ${ }^{[7-9]}$ analyzed the phase equilibrium and growth mechanism of lamellar eutectic for ternary eutectic alloys.

$\mathrm{The} \mathrm{Pb}$-Sb-Sn ternary alloys form a typical eutectic system, which exhibits three primary phase regions in its equilibrium phase diagram. The primary phase and the eutectic morphology are quite different in these three phase zones. $(\mathrm{Pb})$ phase is a non-faceted solid solution phase, $(\mathrm{Sb})$ phase is a classic faceted phase, and SbSn phase is an intermetallic compound. Owing to great difference in the lattice structure and growth mode among these three phases, their coupled growth and structural morphology are extremely complicated. Although some work has been done on the solidification microstructures and physical properties of $\mathrm{Pb}-\mathrm{Sb}$-Sn ternary alloys at near-equilibrium state $^{[12-15]}$, there are few investigations on the rapid solidification of highly undercooled $\mathrm{Pb}-\mathrm{Sb}$-Sn alloys.

An alloy melt can be substantially undercooled to temperatures well below its equilibrium freezing point by eliminating the intrinsic heterogeneous nuclei. The glass fluxing method is an efficient approach to removing heterogeneous nuclei and achieving bulk undercooling, which is applicable to $\mathrm{Pb}-\mathrm{Sb}$-Sn ternary alloys. The objective of this work is to investigate the nucleation mechanism of primary and eutectic phases, reveal the microstructural evolution and solidification routes and explore the solute redistribution characteristics under substantial undercooling conditions.

\section{Experimental procedure}

The experiments were performed by the glass fluxing method. Pb-Sb-Sn ternary alloy samples were prepared from pure $\mathrm{Pb}(99.999 \%), \mathrm{Sb}(99.95 \%)$ and $\mathrm{Sn}(99.9 \%)$. Each sample had the mass of $1 \mathrm{~g}$ and was contained in an $8 \mathrm{ID} \times 10 \mathrm{OD} \times 12 \mathrm{~mm}$ alumina crucible. The sample was covered by $0.2 \mathrm{~g}$ $\mathrm{B}_{2} \mathrm{O}_{3}$ glass as the fluxing agent and melted in a resistance furnace. After being superheated by 200 $\mathrm{K}$ for several minutes, the sample was cooled at a rate of $46-73 \mathrm{~K} / \mathrm{min}$ by rapidly moving the crucible away from the heating source. The process of heating and cooling was repeated for 2 to 5 times. The sample temperature was monitored by a NiCr-NiSi thermocouple and recorded by a 3066 type three-pen recorder.

After experiment, the solidified samples were sectioned and polished. At first, the sample was etched with a solution of $10 \% \mathrm{HCl}$ for $2 \mathrm{~min}$, and subsequently ectched with $10 \mathrm{~g} \mathrm{FeCl}_{3}+2 \mathrm{~mL}$ $\mathrm{HCl}+97 \mathrm{~mL} \mathrm{H}_{2} \mathrm{O}$ for $20 \mathrm{~s}$. The thermodynamic properties were determined with TA Modulated DSC 2910 differential scaning calorimetry analyzer. Its phase constitution was examined with Rigaku D/max 2500 X-ray diffractometer. Microstructural morphologies were analyzed with FEI Sirion 200 scanning electron microscope and Zeiss Axiovert 200MAT optical microscope, and solute distributions were examined with INCA Energy 300 energy dispersive spectrometer.

\section{Results and discussion}

The three alloy compositions chosen for the experimental research are $\mathrm{Pb}-5 \% \mathrm{Sb}-4 \% \mathrm{Sn}$, $\mathrm{Pb}-20 \% \mathrm{Sb}-4 \% \mathrm{Sn}$ and $\mathrm{Pb}-14 \% \mathrm{Sb}-10 \% \mathrm{Sn}$, which correspond to the three primary phase regions of $(\mathrm{Pb}),(\mathrm{Sb})$ and $\mathrm{SbSn}$, respectively. Their locations in the $\mathrm{Pb}-\mathrm{Sb}$-Sn ternary phase diagram are designated as points $A, B$ and $C$ in Figure 1, where Figure 1(a) is the Pb-rich corner of liquidus pro- 
fection and Figure 1(b) is the vertical section along the $M-M$ line in Figure 1(a) ${ }^{[13-15]}$. The maximum undercoolings obtained in this work are $82 \mathrm{~K}\left(0.15 T_{\mathrm{L}}\right), 87 \mathrm{~K}\left(0.15 T_{\mathrm{L}}\right)$ and $68 \mathrm{~K}\left(0.12 T_{\mathrm{L}}\right)$, respectively, for these three alloys.
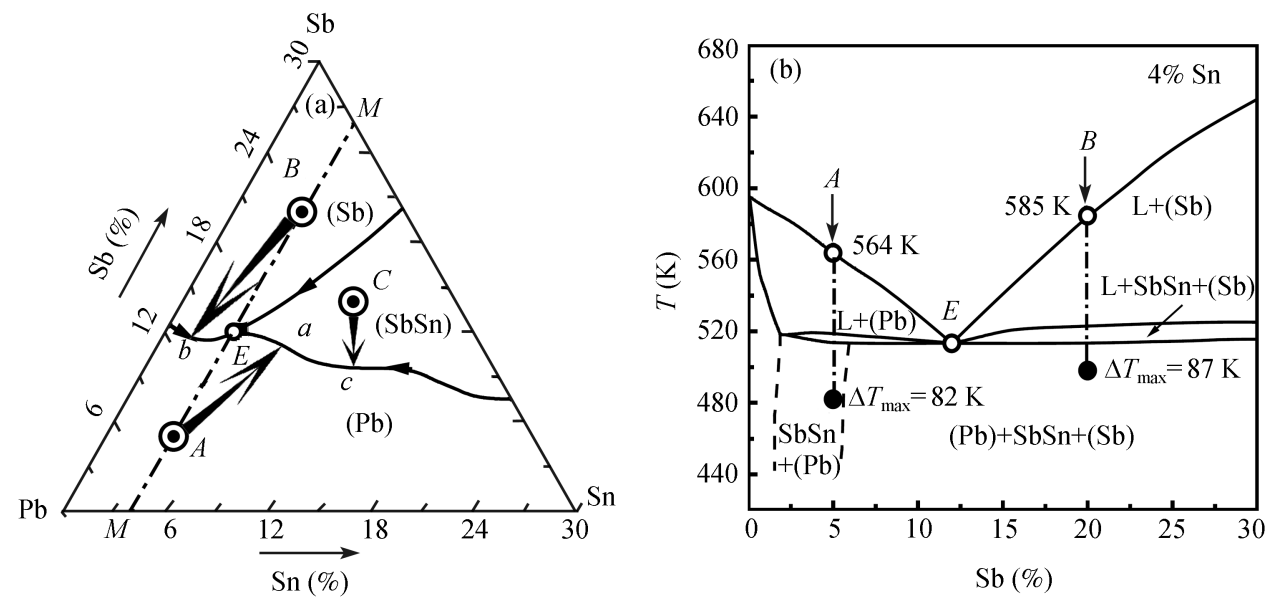

Figure 1 Schematic of three solidification routes. (a) Pb-rich corner of liquidus projection; (b) $M-M$ vertical section.

\subsection{Rapid solidification of undercooled $\mathrm{Pb}-5 \% \mathrm{Sb}-4 \% \mathrm{Sn}$ ternary alloy}

(i) Thermal analysis and phase constitution. The thermal analysis of $\mathrm{Pb}-5 \% \mathrm{Sb}-4 \% \mathrm{Sn}$ ternary alloy was carried out by differential scanning calorimetry (DSC). A sample with the mass of 2.49 $\mathrm{mg}$ was heated and cooled at a rate of $5 \mathrm{~K} / \mathrm{min}$ during the experiment. Its total melting enthalpy is determined as $22.34 \mathrm{~J} / \mathrm{g}$, and the DSC curve is illustrated in Figure 2(a). Apparently, this alloy exhibits two melting peaks and two solidification peaks. The first melting peak takes place at a temperature of $514 \mathrm{~K}$, while the second one appears as a small peak at $550 \mathrm{~K}$. There exist two sharp crystallization peaks at 544 and $510 \mathrm{~K}$, respectively, in the cooling process. The DSC analysis shows that the liquidus temperature is $558 \mathrm{~K}$, and the solidus temperature is $514 \mathrm{~K}$.

The X-ray diffraction (XRD) analyses were performed on the solidified samples with various undercoolings in the range of 10-82 K. XRD patterns are presented in Figure 2(b), which indi-
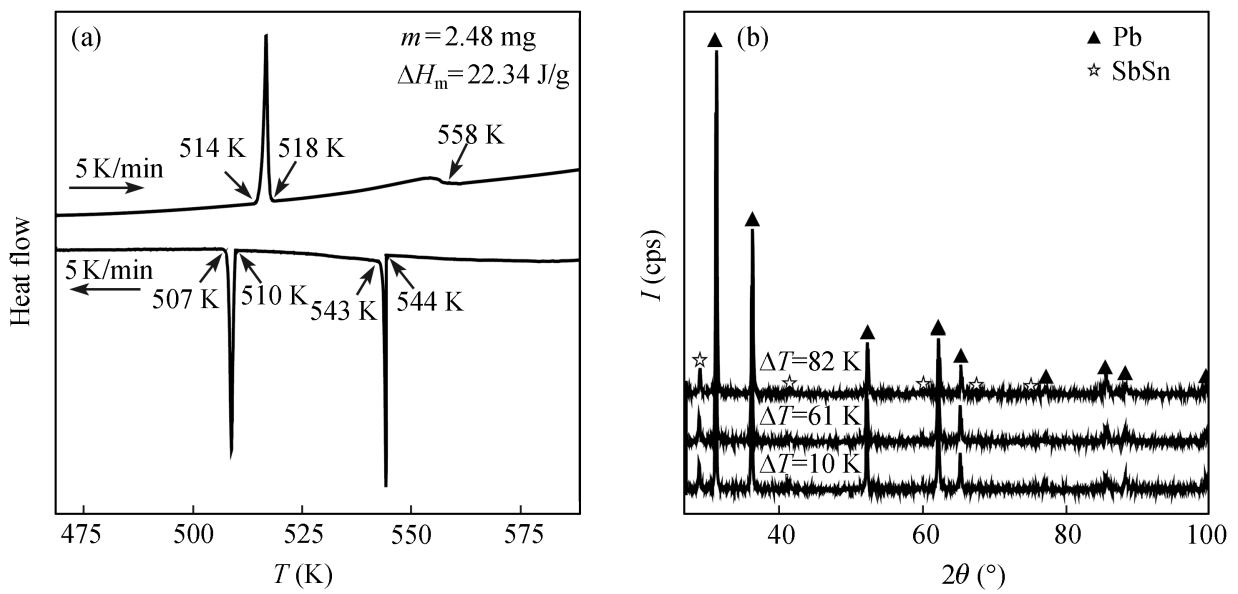

Figure 2 Thermal analysis and X-ray diffraction of $\mathrm{Pb}-5 \% \mathrm{Sb}-4 \% \mathrm{Sn}$ ternary alloy. (a) DSC thermogram; (b) XRD patterns. 
cates that the solidification microstructures obtained within this undercooling range are all composed of $(\mathrm{Pb})$ solid solution phase and $\mathrm{SbSn}$ intermetallic compound phase.

(ii) Structural characteristics of primary $(\mathrm{Pb})$ phase. $\mathrm{Pb}-5 \% \mathrm{Sb}-4 \% \mathrm{Sn}$ alloy is located within the primary $(\mathrm{Pb})$ phase region, and its solidification microstructures consist mainly of primary $(\mathrm{Pb})$ phase and eutectic structure. As seen in Figure $2(\mathrm{a})$, the primary $(\mathrm{Pb})$ phase begins to nucleate when the temperature reduces to $544 \mathrm{~K}$, and the latent heat of crystallization is $7.74 \mathrm{~J} / \mathrm{g}$. The temperature interval between the first and the second exothermic peaks is $34 \mathrm{~K}$, which means that a lot of primary $(\mathrm{Pb})$ phases form in this ternary alloy.

(1) Dendritic microstructures. An evident transition occurs in the microstructure of primary $(\mathrm{Pb})$ phase with the enhancement of undercooling. Figure 3 presents the microstructural variation of $\mathrm{Pb}-5 \% \mathrm{Sb}-4 \% \mathrm{Sn}$ ternary alloy as undercooling increases, where the black phase is the primary $(\mathrm{Pb})$ phase and the white part is the pseudobinary $(\mathrm{Pb})+\mathrm{SbSn}$ eutectic microstructure. When undercooling is small, the $(\mathrm{Pb})$ phase is characterized by coarse and well-developed dendrites. As undercooling increases, the microstructures are significantly refined. If undercooling exceeds a value of about $61 \mathrm{~K}$, the primary $(\mathrm{Pb})$ phase is found to form small equiaxed dendrites. The dendritic structures become homogeneous and equiaxed fragments when the alloy melt is undercooled by $82 \mathrm{~K}$. A measurement has been done to establish the relationship between the average grain size of primary $(\mathrm{Pb})$ phase and undercooling. Figure 4(a) shows the measured results. Evidently, the average grain size of primary $(\mathrm{Pb})$ phase decreases dramatically with undercooling. Figure 3 and Figure 4(a) reveal some characteristics of dendritic fragmentation, indicating that the refinement of microstructures is caused by remelting and ripening of primary dendrites. At small undercoolings, the latent heat of crystallization is efficiently released through the liquid alloy and its surroundings, and the primary $(\mathrm{Pb})$ phase grows directly into coarse dendrites. Once undercooling exceeds $39 \mathrm{~K}$, the rapid release of latent heat results in a strong recalescence effect, which brings about remelting and fragmentation of rapidly growing dendrites. Clearly, the grain structure is refined under rapid solidification and high undercooling conditions.
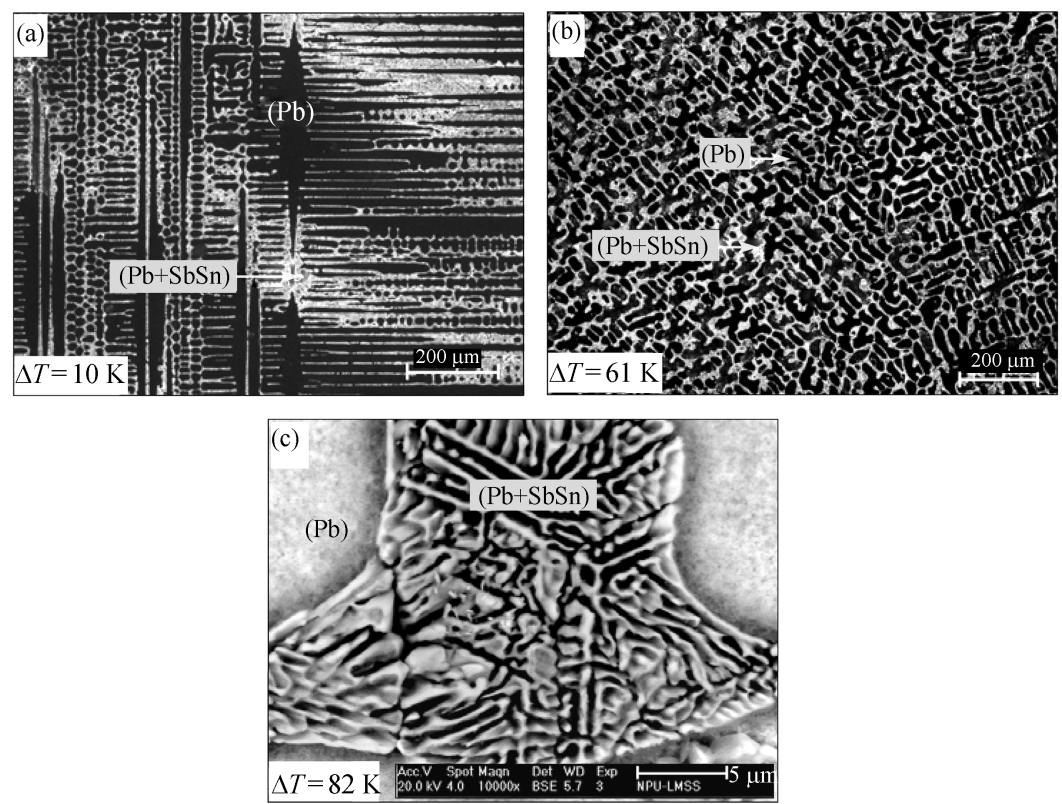

Figure 3 Solidification microstructures of $\mathrm{Pb}-5 \% \mathrm{Sb}-4 \% \mathrm{Sn}$ alloy at different undercoolings. 

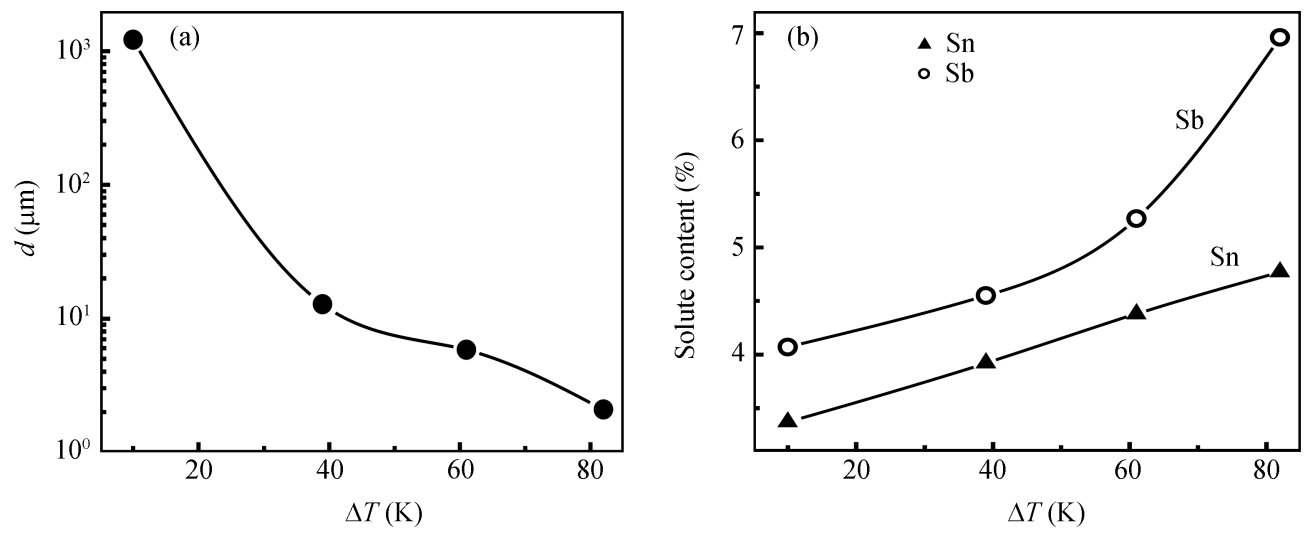

Figure 4 Grain size (a) and solute content (b) versus undercooling.

(2) Solute trapping effect. EDS analysis indicates that remarkable solute trapping occurs during the rapid solidification of $\mathrm{Pb}-5 \% \mathrm{Sb}-4 \% \mathrm{Sn}$ ternary alloy. The contents of solute $\mathrm{Sb}$ and $\mathrm{Sn}$ in $(\mathrm{Pb})$ phase at its grain center are illustrated in Figure 4(b). Obviously, the solute contents increase with undercooling. When alloy undercooling is below $39 \mathrm{~K}$, the contents of $\mathrm{Sb}$ and $\mathrm{Sn}$ are less than the original alloy concentration. However, at the undercooling of $82 \mathrm{~K}$, the solubilities of $\mathrm{Sb}$ and $\mathrm{Sn}$ exceed the original alloy concentration, and they rise up to $6.96 \%$ and $4.59 \%$, respectively. It is apparent that the solute solubility of primary $(\mathrm{Pb})$ phase is effectively extended under rapid solidification and high undercooling conditions.

(iii) Pseudobinary eutectic structures. When the temperature of $\mathrm{Pb}-5 \% \mathrm{Sb}-4 \% \mathrm{Sn}$ alloy falls to $510 \mathrm{~K}$ in the process of solidification, the $(\mathrm{Pb})+\mathrm{SbSn}$ pseudobinary eutectic microstructures grow from the liquid phase whose composition reaches the pseudobinary eutectic line in $\mathrm{Pb}-\mathrm{Sb}$-Sn ternary phase diagram. Since the liquid phase has completely solidified before it attains the ternary eutectic point, no ternary eutectic microstructures are produced in $\mathrm{Pb}-5 \% \mathrm{Sb}-4 \% \mathrm{Sn}$ alloy. The microstructural morphologies of $(\mathrm{Pb})+\mathrm{SbSn}$ pseudobinary eutectic are shown in Figure 3(c), where lamellar eutectics mainly appear around the primary $(\mathrm{Pb})$ phase.

The phase constitution and the solute distribution of $(\mathrm{Pb})+\mathrm{SbSn}$ lamellar eutectic are determined by EDS scanning analyses, as shown in Figure 5, where the dark phase is $(\mathrm{Pb})$ solid solution, and the white one is $\mathrm{SbSn}$ intermetallic compound. $(\mathrm{Pb})$ and $\mathrm{SbSn}$ phases grow cooperatively in a lamellar way. As is obvious in Figure 5(b) and (c), the solubility of Sb is higher than that of Sn in $\mathrm{SbSn}$ intermetallic compound.

Figure 6 presents the relationship of $(\mathrm{Pb}+\mathrm{SbSn})$ pseudobinary eutectic and undercooling. As undercooling increases, the volume fraction of pseudobinary eutectic decreases, which follows a linear relation:

$$
f_{\mathrm{BE}}=0.57-0.0084 \Delta T \text {. }
$$

(iv) Nucleation mechanism and solidification route. $\mathrm{The}(\mathrm{Pb}+\mathrm{SbSn})$ pseudobinary eutectic structures appear around the primary $(\mathrm{Pb})$ phase, and the edge of $(\mathrm{Pb})$ dendrites grows smoothly. It is obvious that primary $(\mathrm{Pb})$ phase is not an effective heterogeneous nucleus for the intermatellic compound SbSn phase, just as shown in Figure 3. By comparing Figure 4(b) with Figure 6, it can be clearly seen that the solubility of $\mathrm{Sb}$ increases but the volume fraction of $(\mathrm{Pb}+\mathrm{SbSn})$ pseudobinary eutectic decreases with undercooling, which keeps the mass conservation of $\mathrm{Pb}-5 \% \mathrm{Sb}-4 \% \mathrm{Sn}$ ternary alloy. 

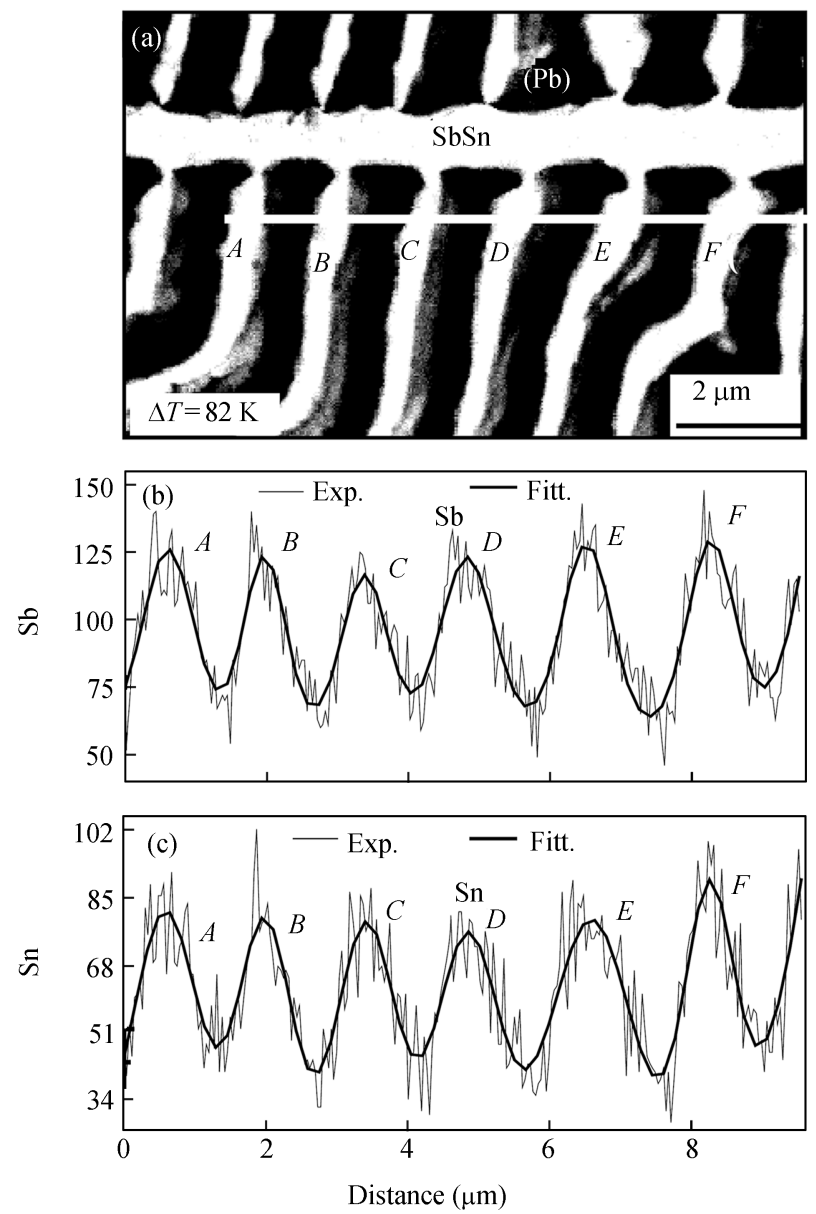

Figure 5 Solute distribution of $(\mathrm{Pb})+\mathrm{SbSn}$ pseudobinary eutectic structure. (a) EDS scanning line; (b) profile of Sb content; (c) profile of Sn content.

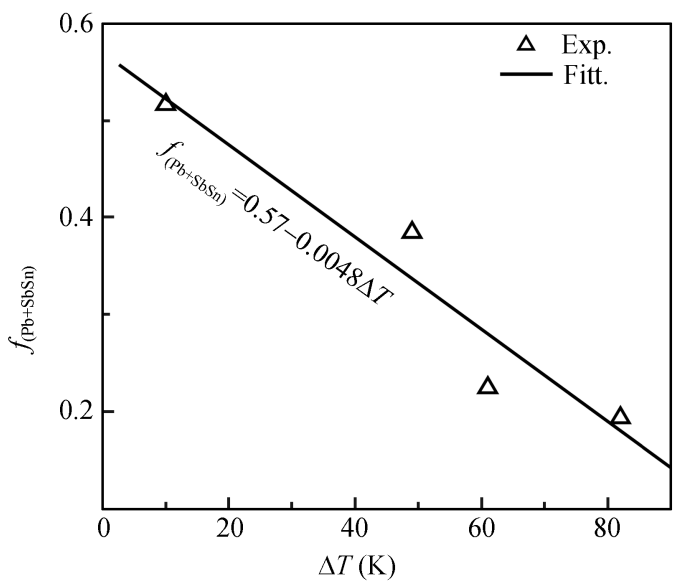

Figure 6 Volume fraction of $(\mathrm{Pb}+\mathrm{SbSn})$ pseudobinary eutectic structure at different undercoolings.

The solidification route is illustrated in Figure 1(a), which shows that the concentration and temperature of $\mathrm{Pb}-5 \% \mathrm{Sb}-4 \% \mathrm{Sn}$ ternary alloy change along line $A a$. The $(\mathrm{Pb}+\mathrm{SbSn})$ eutectic 
structure starts to grow when the concentration and temperature of remnant liquid phase reach the pseudobinary eutectic line. Subsequently this kind of pseudobinary eutectic grows continuously. The solidification process is completely finished before the concentration and temperature arrive at the ternary eutectic point, which explains why no ternary eutectics form in the undercooled $\mathrm{Pb}-5 \% \mathrm{Sb}-4 \% \mathrm{Sn}$ ternary alloy.

\subsection{Primary phase and eutectic structure of $\mathrm{Pb}-20 \% \mathrm{Sb}-4 \% \mathrm{Sn}$ ternary alloy}

(i) Thermodynamic property and phase constitution. Differential scanning calorimetry (DSC) was applied to investigating the thermodynamic property of $\mathrm{Pb}-20 \% \mathrm{Sb}-4 \% \mathrm{Sn}$ ternary alloy. The sample has the mass of $2.49 \mathrm{mg}$, which was heated and cooled at a rate of $5 \mathrm{~K} / \mathrm{min}$ during the experiment. As shown in Figure 7, the melting-cooling curves show three melting and three crystallization peaks, indicating that the phase transformation occurs three times. Clearly, the melting temperatures are 512,514 and $519 \mathrm{~K}$, respectively, and the total heat of fusion is $35.78 \mathrm{~J} / \mathrm{g}$. In the cooling process, the crystallizing temperatures are 570,513 and $510 \mathrm{~K}$, respectively, and the third exothermal peak is very sharp. The liquidus temperature of the $\mathrm{Pb}-20 \% \mathrm{Sb}-4 \% \mathrm{Sn}$ ternary alloy is determined as $570 \mathrm{~K}$, while the solidus temperature is $512 \mathrm{~K}$.
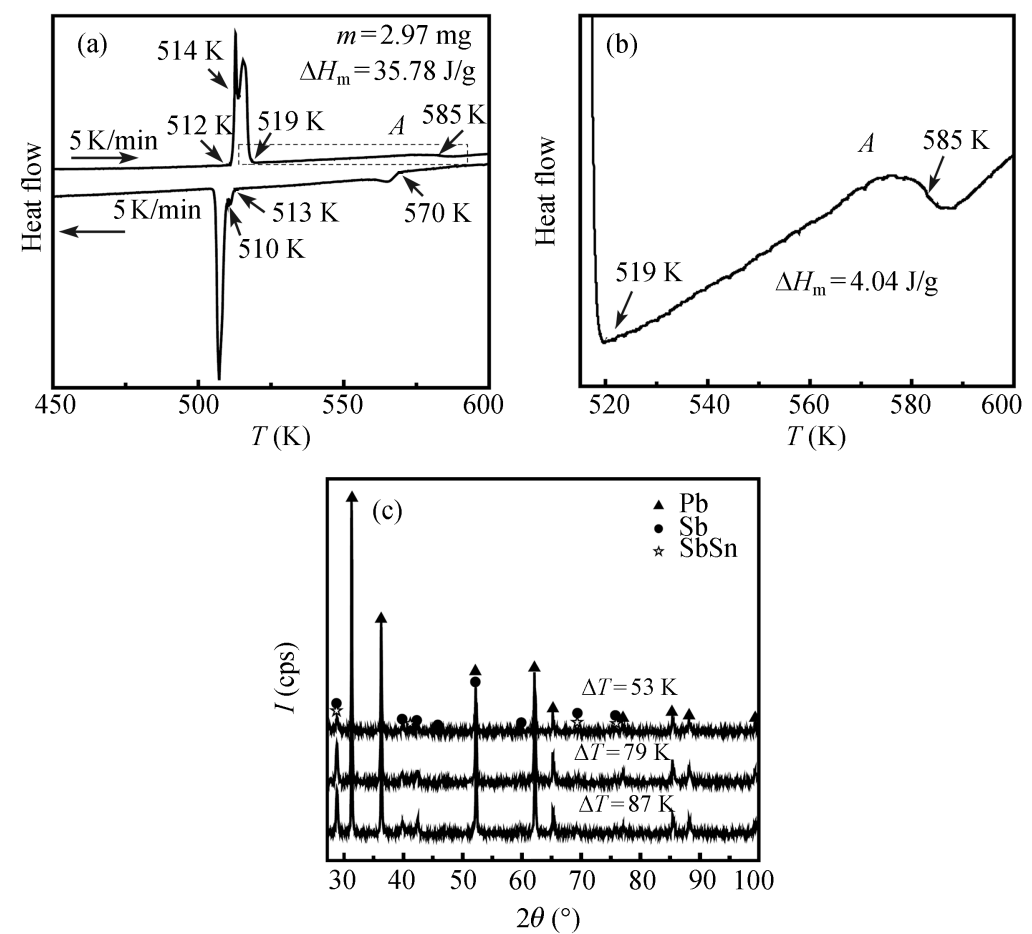

Figure 7 Thermal analysis and X-ray diffraction of $\mathrm{Pb}-20 \% \mathrm{Sb}-4 \% \mathrm{Sn}$ ternary alloy. (a) DSC thermogram; (b) enlarged part of DSC curve; (c) XRD pattern.

In order to explore the phase constitution of $\mathrm{Pb}-20 \% \mathrm{Sb}-4 \% \mathrm{Sn}$ ternary alloy, $\mathrm{XRD}$ diffraction analyses have been accomplished. Figure 7(c) presents the XRD patterns of several samples with different undercoolings. It is evident that solidification microstructures always consist of $(\mathrm{Pb})$ solid solution, ( $\mathrm{Sb}$ ) solid solution and $\mathrm{SbSn}$ intermetallic compound.

(ii) Structural morphology of primary ( $\mathrm{Sb}$ ) phase. $\mathrm{Pb}-20 \% \mathrm{Sb}-4 \% \mathrm{Sn}$ ternary alloy is selected from the primary $(\mathrm{Sb})$ phase region in the $\mathrm{Pb}-\mathrm{Sb}$-Sn ternary phase diagram. When the sample 
temperature decreases to $570 \mathrm{~K}$, the primary $(\mathrm{Sb})$ phase grows in the faceted mode as the preceding nucleation phase, and the latent heat of crystallization is $4.21 \mathrm{~J} / \mathrm{g}$. The temperature interval is $57 \mathrm{~K}$ between the first and the second exothermic peaks, indicating that a lot of primary phases $(\mathrm{Sb})$ form in $\mathrm{Pb}-20 \% \mathrm{Sb}-4 \% \mathrm{Sn}$ ternary alloy.

(1) Structural characteristics. Figure 8(a) and (b) presents the structural morphology of faceted $\mathrm{Sb}$ ) phase. The primary phase grows into either faceted polygonal blocks or faceted long strips and appears as the white structures in optical micrographs. Figure 9 demonstrates the relationship between the volume fraction of polygonal faceted $(\mathrm{Sb})$ blocks and undercooling. It indicates that the volume fraction of polygonal faceted ( $\mathrm{Sb}$ ) phase decreases with undercooling. The polygonal faceted $(\mathrm{Sb})$ phase occupies $15 \%$ volume in the solidified structures when undercooling is $53 \mathrm{~K}$, and grows at the upper part of the sample. Usually, there are also some polygonal $(\mathrm{Sb})$ blocks attached to the faceted $(\mathrm{Sb})$ strips. However, the volume fraction of polygonal faceted $(\mathrm{Sb})$ phase becomes only $3.03 \%$ when undercooling increases to $87 \mathrm{~K}$. It is evident that the high undercooling condition suppresses the growth of polygonal faceted $(\mathrm{Sb})$ phase and promotes the formation of faceted $(\mathrm{Sb})$ strips. With the increase of undercooling, the volume fraction of polygonal faceted $(\mathrm{Sb})$ phase decreases according to the following relation:

$$
f_{\text {(Sb) }}=0.67-0.01 \Delta T+8.13 \times 10^{-5} \Delta T^{2} .
$$
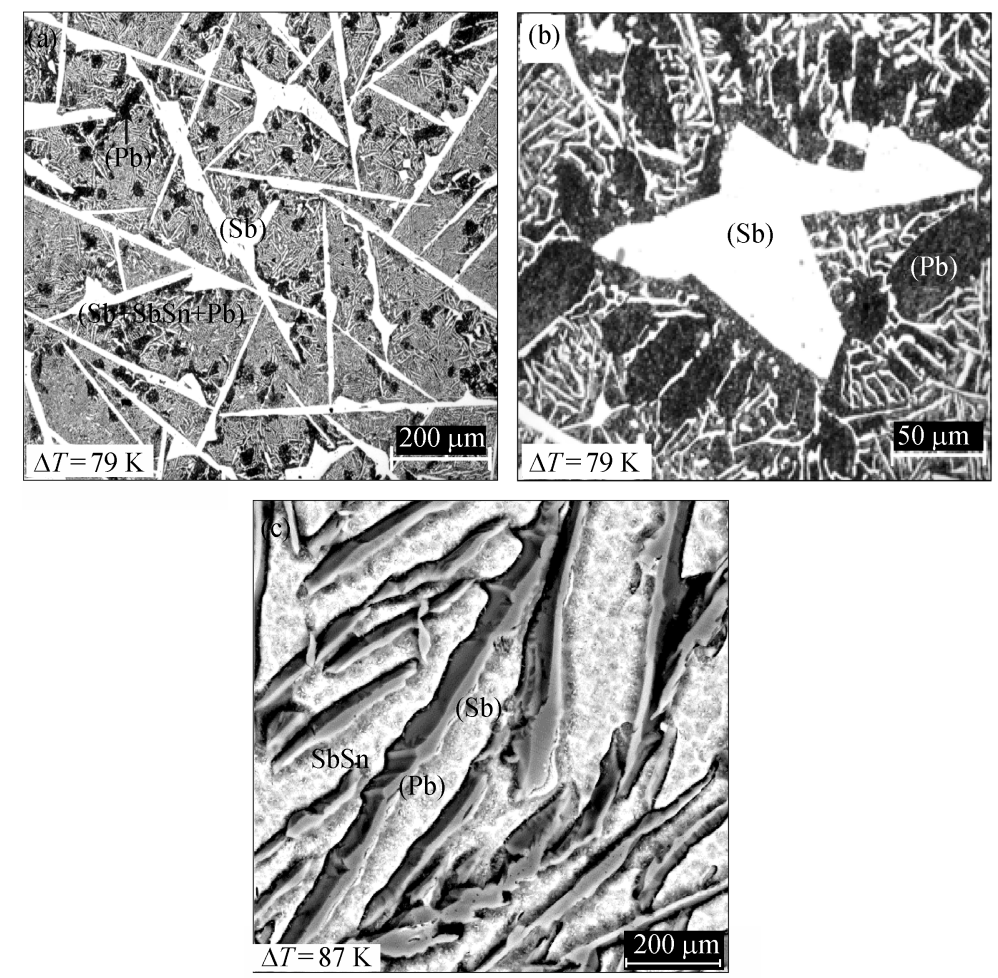

Figure 8 Structural morphologies of $\mathrm{Pb}-20 \% \mathrm{Sb}-4 \% \mathrm{Sn}$ ternary alloy. (a) Low magnification structure; (b) primary phases; (c) ternary eutectic structure.

(2) Solute trapping effect. EDS line scan analysis shows that the solubility of Sn is larger than that of $\mathrm{Pb}$ in the primary polygonal ( $\mathrm{Sb}$ ) blocks, just as shown in Figure 10. The actual contents of both solutes $\mathrm{Sn}$ and $\mathrm{Pb}$ in primary $(\mathrm{Sb})$ phase are also determined and the results are shown in 


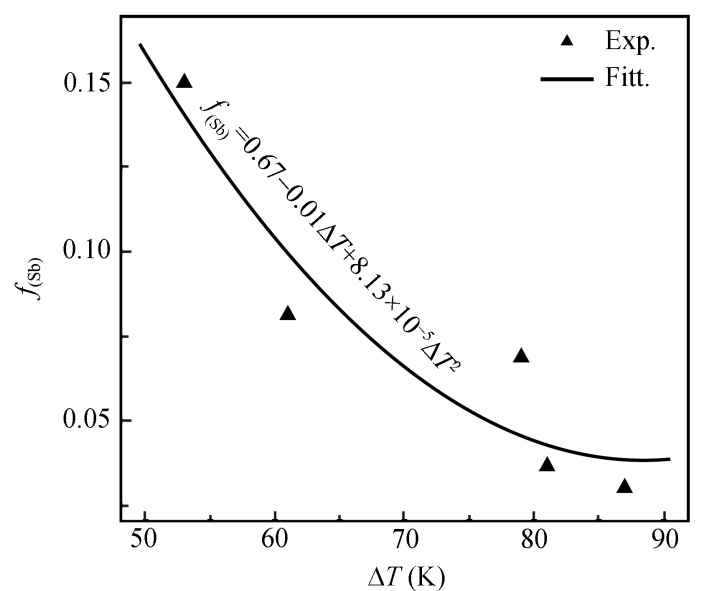

Figure 9 Volume fraction of polygonal primary $(\mathrm{Sb})$ blocks versus undercooling.
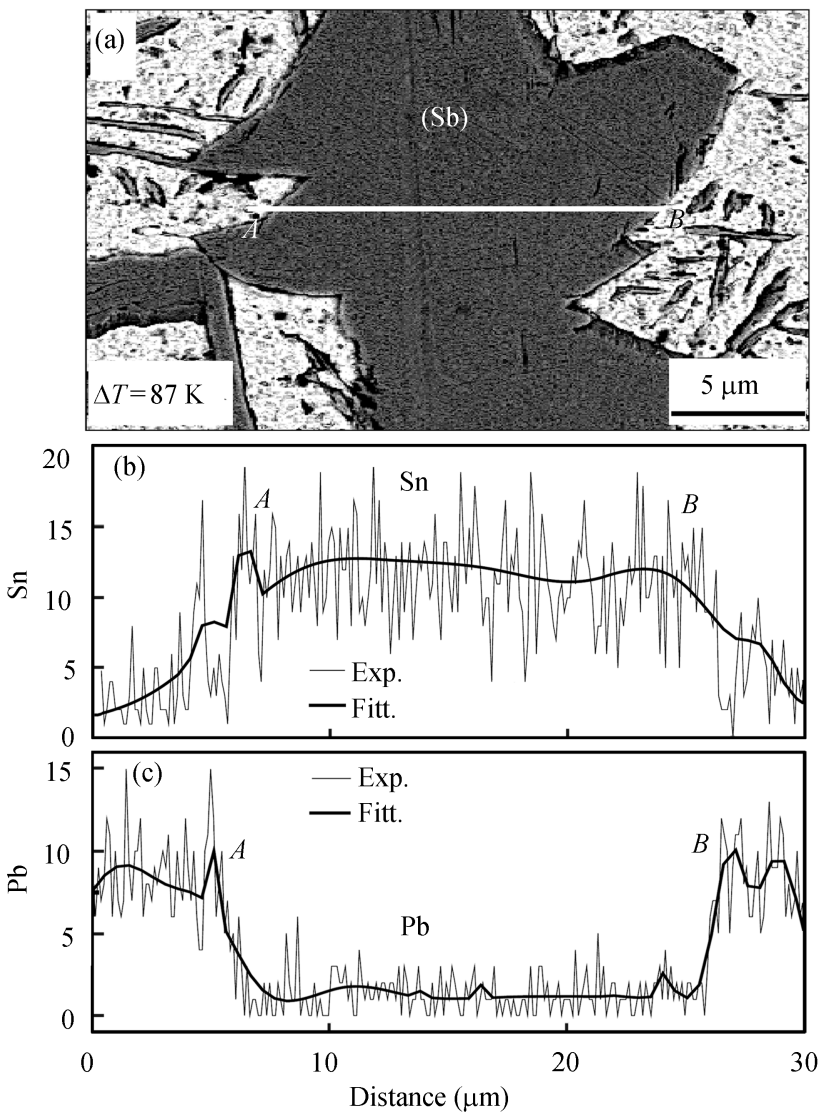

Figure 10 Solute distribution of primary (Sb) phase. (a) EDS scanning line; (b) Sn distribution; (c) Pb distribution.

Figure 11. It is apparent that the solute contents of primary $(\mathrm{Sb})$ phase increase with undercooling. According to the $\mathrm{Pb}-\mathrm{Sb}$ and $\mathrm{Pb}-\mathrm{Sn}$ binary phase diagrams, the maximum solubilities of $\mathrm{Pb}$ and $\mathrm{Sn}$ inside $(\mathrm{Sb})$ phase are $3.24 \%$ and $9 \%$, respectively. At undercooling of $53 \mathrm{~K}$, the $\mathrm{Pb}$ content in primary $(\mathrm{Sb})$ phase is $2.83 \%$. This solute content becomes $3.64 \%$ when undercooling rises up to $81 \mathrm{~K}$. At the large undercooling of $87 \mathrm{~K}$, the solubility of $\mathrm{Pb}$ inside the primary $(\mathrm{Sb}$ ) phase is ex- 

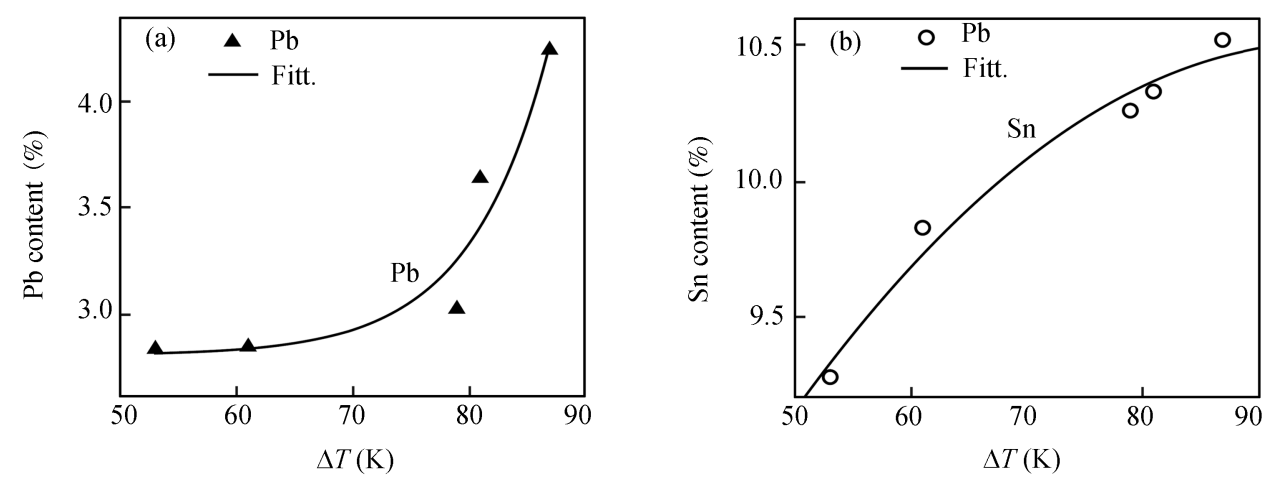

Figure 11 Solute contents of primary (Sb) phase as a function of undercooling. (a) Solute Pb; (b) solute Sn.

tended to $4.25 \%$. Similarly, the Sn content in primary ( $\mathrm{Sb}$ ) phase also exhibits an obvious increasing tendency. In the sample undercooled by $53 \mathrm{~K}$, the primary ( $\mathrm{Sb}$ ) phase contains $9.28 \% \mathrm{Sn}$. But the Sn content of $(\mathrm{Sb})$ phase increases to $10.52 \%$ when the ternary alloy is undercooled by $87 \mathrm{~K}$. These measured results of EDS analyses have shown that the rapid solidification induced by high undercooling leads to the remarkable extension of solute solubilities within primary $(\mathrm{Sb})$ phase.

(iii) Pseudobinary eutectic morphology. Figures $8(\mathrm{a})$ and (b) show that $\mathrm{Pb}$ phase grows around the primary $(\mathrm{Sb})$ phase. The white and dark phases are the solid solution $(\mathrm{Sb})$ and $(\mathrm{Pb})$ phases respectively in these two optical micrographs. Since the primary $(\mathrm{Sb})$ phase has a rather large solidification temperature range and it consumes large quantities of $\mathrm{Sb}$ atoms to grow up, $\mathrm{Pb}$ atoms become enriched in the liquid phase surrounding the primary $(\mathrm{Sb})$ phase. Once temperature drops down to $513 \mathrm{~K}$, the liquid phase concentration attains the $(\mathrm{Pb}+\mathrm{Sb})$ pseudobinary eutectic line. In such a case, $(\mathrm{Pb})$ phase nucleates independently and grows in a dendritic way in the vicinity of primary $(\mathrm{Sb})$ phase, resulting in the formation of $(\mathrm{Pb})+(\mathrm{Sb})$ divorced eutectic. This is quite different from the prediction of Figure 1(b) that (Sb)+SbSn pseudobinary eutectic should have formed under the equilibrium condition. The direct reason is that the extremely nonequilibrium condition produced by substantial undercooling has drastically changed the actual solidification route of $\mathrm{Pb}-20 \% \mathrm{Sb}-4 \% \mathrm{Sn}$ ternary alloy.

(iv) Ternary eutectic microstructure. As seen in Figure $7(\mathrm{a}),(\mathrm{Pb})+(\mathrm{Sb})+\mathrm{SbSn}$ ternary eutectic structures start to form when the temperature reduces to $510 \mathrm{~K}$. The ternary eutectic transformation has aroused a sharp exothermal peak, and the latent heat of crystallization is $31.64 \mathrm{~J} / \mathrm{g}$, which indicates that a large amount of ternary eutectic structures are produced in $\mathrm{Pb}-20 \% \mathrm{Sb}-4 \% \mathrm{Sn}$ ternary alloy. Figure $8(\mathrm{c})$ is the back scattering electron micrograph of the $(\mathrm{Pb})+(\mathrm{Sb})+\mathrm{SbSn}$ ternary eutectics distributed within the interspacings of $(\mathrm{Pb})+(\mathrm{Sb})$ pseudobinary eutectics shown in Figure 8(a). Here the white phase is $(\mathrm{Pb})$ phase, the dark grey phase is $\mathrm{SbSn}$ intermetallic compound, and the bright grey phase is $(\mathrm{Sb})$ phase. It is apparent that $(\mathrm{Sb})$ and $\mathrm{SbSn}$ phases have nucleated and grown dependently. Figure 8(a) also shows that there are a lot of ternary eutectic microstructures between the $(\mathrm{Pb})+(\mathrm{Sb})$ pseudobinary eutectic colonies, which agrees well with the DSC experiment of Figure 7(a). The alternating nucleation and cooperative growth of $(\mathrm{Pb}),(\mathrm{Sb})$ and $\mathrm{SbSn}$ phases results in the formation of lamellar ternary eutectics.

Figure 12 gives the volume fraction of ternary eutectics at different undercoolings. It can be seen that the volume fraction of $(\mathrm{Pb})+(\mathrm{Sb})+\mathrm{SbSn}$ eutectics increases dramatically with undercooling. This is because a large number of primary polygonal $(\mathrm{Sb})$ blocks are formed together with lots of 
$(\mathrm{Pb})$ phase under a small undercooling condition, and consequently there remain few interspaces for ternary eutectics. As shown in Figure 13, the primary ( $\mathrm{Sb}$ ) strips increase their interspacings when the primary polygonal $(\mathrm{Sb})$ blocks reduce their volume fraction at large undercoolings. Therefore, more ternary eutectics can form accordingly. The volume fraction of ternary eutectics varies with undercooling according to the following relation:

$$
f_{\mathrm{TE}}=-0.94+0.03 \Delta T-1.81 \times 10^{-4} \Delta T^{2} .
$$

(v) Nucleaion characteristics and solidification route. In the solidification process of $\mathrm{Pb}-20 \% \mathrm{Sb}-4 \% \mathrm{Sn}$ ternary alloy, the primary $(\mathrm{Sb})$ phase nucleates preferentially in alloy melt and grows into faceted strips and polygonal blocks. Meanwhile, $(\mathrm{Pb})$ phase also nucleates independently and grows up in the surroundings of primary ( $\mathrm{Sb}$ ) phase. There are no traces of attached or dependent nucleation at the smooth edges of both $(\mathrm{Sb})$ and $(\mathrm{Pb})$ phase. This means that they are not effective heterogeneous nucleus for each other. On the other hand, $(\mathrm{Pb})+(\mathrm{Sb})+\mathrm{SbSn}$ ternary eutectics have formed in the interspaces of $(\mathrm{Pb})+(\mathrm{Sb})$ pseudobinary eutectic colonies, suggesting that primary $(\mathrm{Sb})$ phase should not be an efficient heterogeneous nucleant for $\mathrm{SbSn}$ phase either. In addition, the rapid solidification of this undercooled ternary alloy yields $(\mathrm{Pb})+(\mathrm{Sb})$ rather than (Sb)+SbSn psuedobinary eutectic microstructures.

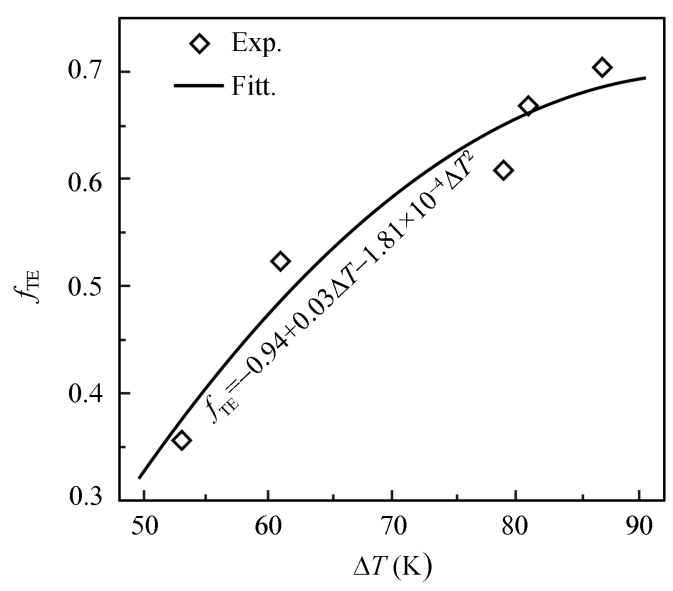

Figure 12 Volume fraction of ternary eutectics in $\mathrm{Pb}-20 \% \mathrm{Sb}-4 \% \mathrm{Sn}$ alloy at different undercoolings.

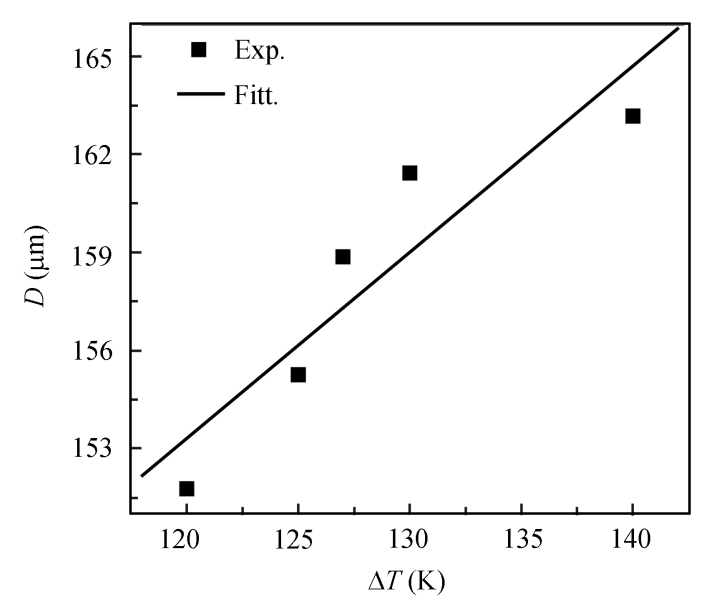

Figure 13 Interspacing of primary $(\mathrm{Sb})$ strips versus undercooling.

The solidification route of $\mathrm{Pb}-20 \% \mathrm{Sb}-4 \% \mathrm{Sn}$ ternary alloy is schematically presented in Figure 1(a). When the alloy temperature falls to $570 \mathrm{~K}$, primary $(\mathrm{Sb})$ phase precipitates from alloy melt and its solidification route proceeds along the $B b$ line. As soon as the concentration and temperature arrive at point $b$ of the $(\mathrm{Pb})+(\mathrm{Sb})$ pseudobinary eutectic line, $(\mathrm{Pb})$ phase begins to nucleate and divorced eutectics come into being. Later on, the solidification process continues along line $b E$ until the ternary eutectic point $E$, where $(\mathrm{Pb})+(\mathrm{Sb})+\mathrm{SbSn}$ ternary eutectics form and put an end to solidification.

It should be pointed out that there is a great difference between the equilibrium solidification route and the actual solidification route of undercooled $\mathrm{Pb}-20 \% \mathrm{Sb}-4 \% \mathrm{Sn}$ ternary alloy. At equilibrium state, $(\mathrm{Sb})+\mathrm{SbSn}$ pseudobinary eutectics are usually formed, because the concentration and temperature will attain the $(\mathrm{Sb})+\mathrm{SbSn}$ pseudobinary eutectic line. However, the substantial undercooling causes the extremely nonequilibrium condition. This makes the concentration and 
temperature vary in such a way that they reach the $(\mathrm{Pb})+(\mathrm{Sb})$ pseudobinary eutectic line, leading to the formation of $(\mathrm{Pb})+(\mathrm{Sb})$ eutectic microstructures.

\subsection{Microstructure and macrosegregation of $\mathrm{Pb}-14 \% \mathrm{Sb}-10 \% \mathrm{Sn}$ ternary alloy}

(i) Thermodynamic property and phase constitution. $\mathrm{Pb}-14 \% \mathrm{Sb}-10 \% \mathrm{Sn}$ ternary alloy is located in the primary SbSn phase region. A sample of $2.92 \mathrm{mg}$ is employed for DSC analysis. The heating and cooling rates are both $5 \mathrm{~K} / \mathrm{min}$. DSC curves are presented in Figure 14(a) and (b). There are three endothermic peaks and four exothermic peaks, showing the complexity of the alloy microstructure. The first two endothermic peaks are not separated, the second endothermic peak corresponds to the melting of main structures, whereas the third peak is only a weak melting process initiated at $518 \mathrm{~K}$. The total enthalpy of the whole melting process is $38.68 \mathrm{~J} / \mathrm{g}$. In the solidification process, the starting temperatures of the four exothermic peaks are 525, 514, 513 and $509 \mathrm{~K}$, respectively. Obviously, the third crystallizing peak coincides with the formation of major solidification microstructures. According to these DSC analyses, the liquidus and solidus temperature of this ternary alloy are determined to be 543 and $512 \mathrm{~K}$.
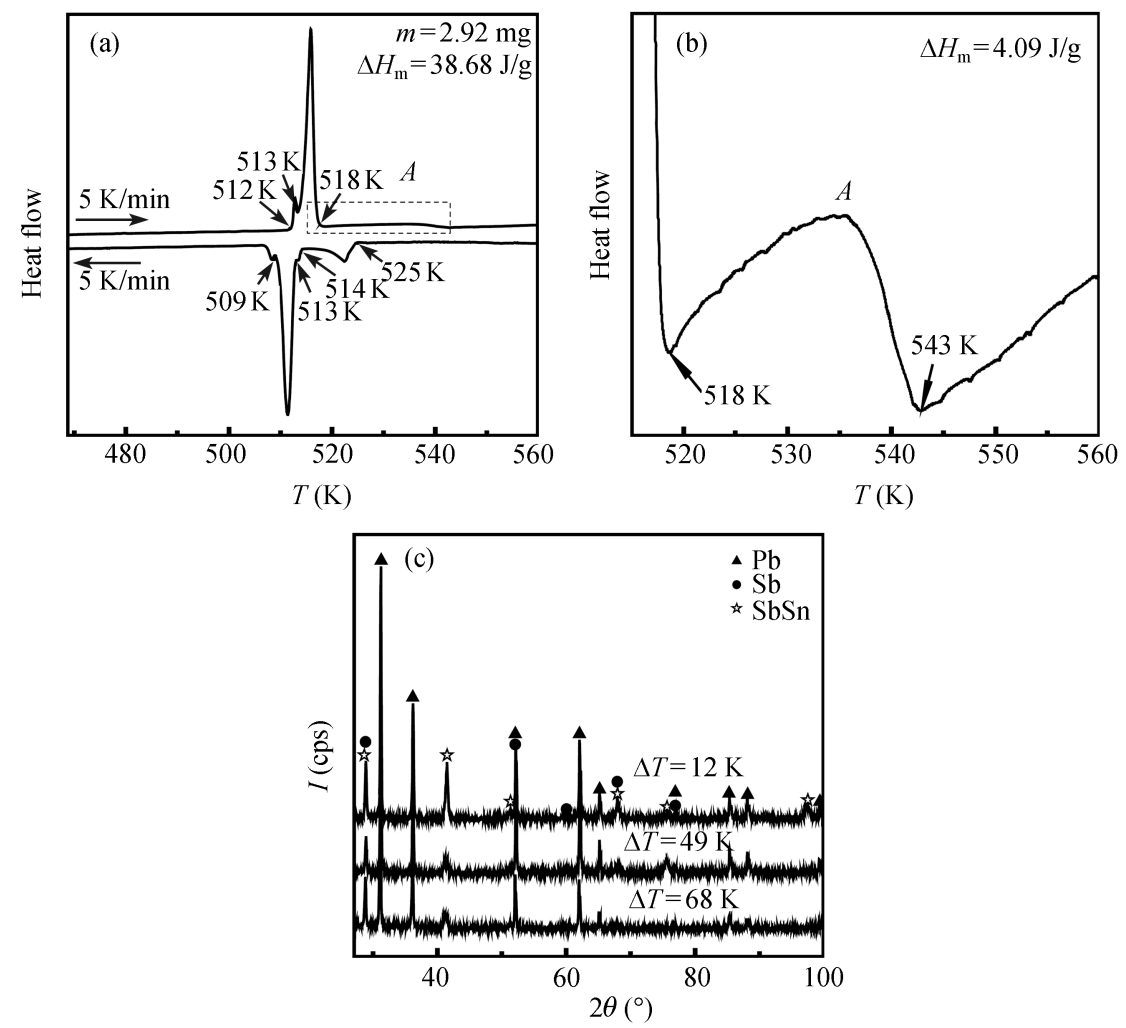

Figure 14 Thermal analysis and XRD diffraction of Pb-14\%Sn-10\%Sn ternary alloy. (a) DSC thermogram; (b) enlarged part of DSC curve; (c) XRD patterns.

The XRD experimental results are shown in Figure 14(c). It is concluded that the solidification structures of $\mathrm{Pb}-14 \% \mathrm{Sb}-10 \% \mathrm{Sn}$ ternary alloy consist of $\mathrm{SbSn}$ intermetallic compound, $(\mathrm{Pb})$ and (Sb) solid solution phases under various undercooling conditions.

(ii) Microstructural morphology of primary SbSn phase. It is known from the DSC curves of Figure 14(a) that primary $\mathrm{SbSn}$ phase begins to nucleate when the temperature of 
$\mathrm{Pb}-14 \% \mathrm{Sb}-10 \% \mathrm{Sn}$ ternary alloy falls to $525 \mathrm{~K}$. The latent heat is $4.27 \mathrm{~J} / \mathrm{g}$ for this primary phase. Because the temperature interval is only $11 \mathrm{~K}$ between the first and second exothermic peaks, there should not be a large amount of primary SbSn intermetallic compounds.

(1) Morphology of solidified microstructures. The microstructures of $\mathrm{Pb}-14 \% \mathrm{Sb}-10 \% \mathrm{Sn}$ ternary alloy display serious macrosegregation, and primary $\mathrm{SbSn}$ phase grows in different manners at the upper and lower parts of an undercooled sample as illustrated in Figure 15(a). At the upper part, primary SbSn phase appears as coarse dendrites and polygonal faceted blocks. The polygonal faceted SbSn blocks are so arranged that they form a sort of discontinous dendrites, with their interspacings filled with $(\mathrm{Pb})$ phase. At the lower part of the undercooled sample, the primary SbSn phase takes the shape of triangular stars. Some of these triangular stars are connected in such a way that they look like fish bones, which is evident in Figure 15(a).
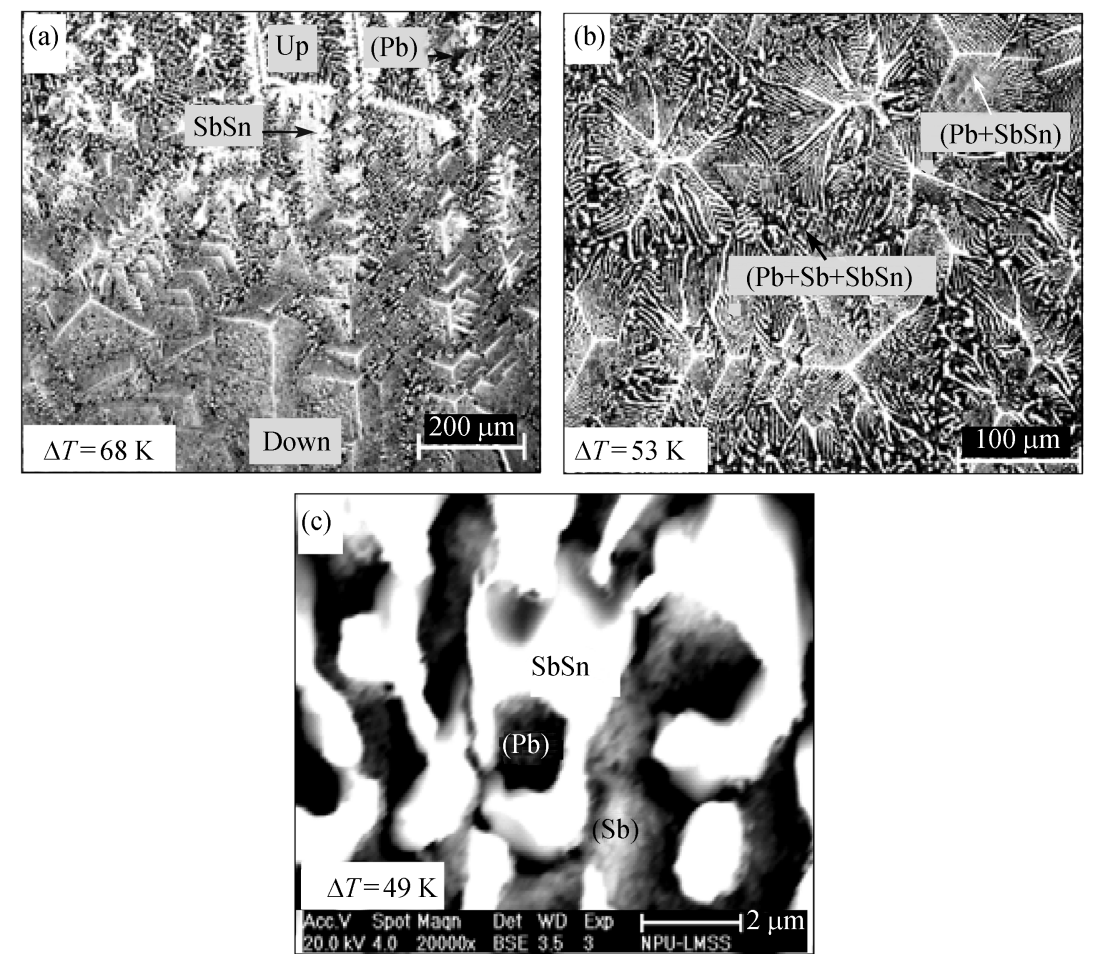

Figure 15 Solidification microstructure of $\mathrm{Pb}-14 \% \mathrm{Sb}-10 \% \mathrm{Sn}$ ternary alloy. (a) Macrosegregation; (b) pseudobinary eutectic; (c) ternary eutectic.

(2) Solute trapping effect. The EDS measurement results show that the $\mathrm{Pb}$ content in primary SbSn phase exhibits an ascending tendency with the increase of undercooling (Figure 16). From the equilibrium $\mathrm{Pb}-\mathrm{Sb}$ and $\mathrm{Pb}-\mathrm{Sn}$ phase diagrams, it is inferred that the maximum $\mathrm{Pb}$ solubility in (Sb) and ( $\mathrm{Sn}$ ) phases is $3.24 \%$ and $2.5 \%$, respectively. The primary SbSn phase is an intermetallic compound with a stable crystalline structure and cannot dissolve too much solute under the equilibrium condition. However, $\mathrm{Pb}$ element can be efficiently dissolved into primary $\mathrm{SbSn}$ phase during high undercooling and rapid solidification. When undercooling is $12 \mathrm{~K}$, the $\mathrm{Pb}$ content is $10.26 \%$. As undercooling increases to $68 \mathrm{~K}$, the $\mathrm{Pb}$ content attains $12.06 \%$. It is apparent that the solute solubility of primary SbSn phase can be extended under rapid solidification conditions.

(iii) Macrosegregation of SbSn phase. The densities of the three solid phases and one liquid 


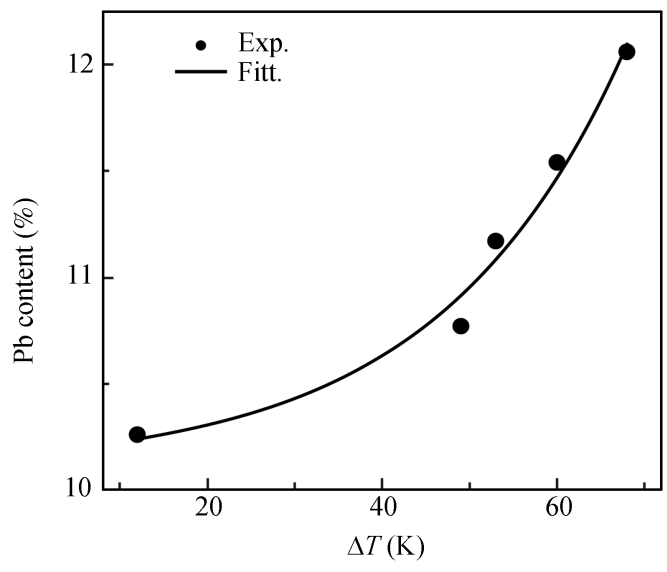

Figure $16 \mathrm{~Pb}$ content of primary SbSn phase at different undercoolings.

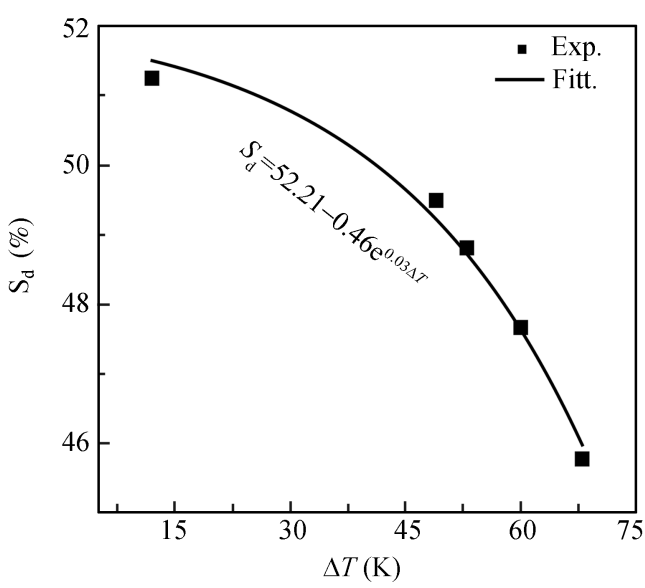

Figure 17 Macrosegregation versus undercooling.

phase in solidifying $\mathrm{Pb}-14 \% \mathrm{Sb}-10 \% \mathrm{Sn}$ ternary alloy are quite different from each other. $\mathrm{SbSn}$ phase is the lightest one among them. It floats to the upper part of the solidifying sample and causes macrosegregation during solidification. The macrosegregation of this ternary alloy is characterized by the inhomogeneuous variation of microstructures along the vertical direction. There is a visible boundary between the two segregated parts: the upper part is enriched with $\mathrm{SbSn}$ phase; whereas the lower part is depleted of SbSn phase.

For the convenience of theoretical analyses, the ratio $S_{\mathrm{d}}$ of the upper segregated part height $h$ to sample height $H$ is defined as the degree of macrosegregation, i.e. $S_{\mathrm{d}}=h / H$. The relationship between $S_{\mathrm{d}}$ and undercooling is illustrated in Figure 17. It can be seen that the degree of macrosegregation decreases with the increase of undercooling. In the case of small undercoolings, the primary SbSn phase has smaller density because of its less $\mathrm{Pb}$ solubility and floats to the sample top by Stokes motion to form coarse dendritic structures there. At large undercoolings, the dendrite fragmentation occurs in primary $\mathrm{SbSn}$ phase owing to the rapid recalescence effect. Meanwhile, the $\mathrm{Pb}$ solubility in $\mathrm{SbSn}$ phase is extended and results in the reduction of density difference between primary SbSn phase and its surrounding liquid phase. Some of the SbSn dendritic fragments exist at the middle and lower parts of alloy sample to form the triangular star microstructures. The macrosegregation degree is consequently reduced. This indicates that the rapid solidification at substantial undercoolings may facilitate the suppression of macrosegregation.

(iv) Evolution of psedobinary eutectics. Because $\mathrm{Pb}$ atoms are expelled from the growing $\mathrm{SbSn}$ dendrites or blocks, they become accumulated ahead of the solid/liquid interface of primary $\mathrm{SbSn}$ phase. When the alloy temperature decreases to $514 \mathrm{~K},(\mathrm{~Pb})$ phase nucleates from the liquid phase with a favourable concentration and grows dendritically. Although it does not form by coupled growth together with $\mathrm{SbSn}$ phase, $(\mathrm{Pb})$ phase depends on $\mathrm{SbSn}$ phase to acquire the desirable concentration condition. The divorced $(\mathrm{Pb})+\mathrm{SbSn}$ pseudobinary eutectics result from this sort of weakly dependent growth of these two phases. At the temperature of $513 \mathrm{~K}$, the liquid concentration arrives at $(\mathrm{Pb})+\mathrm{SbSn}$ pseudobinary eutectic line. According to the DSC curves of Figure 14(a), the corresponding exothermic peak is very sharp and strong, indicating that a great number of $(\mathrm{Pb})+\mathrm{SbSn}$ eutectic structures have been produced. The measured solidification temperature range is $4 \mathrm{~K}$, while the heat of fusion is $34.68 \mathrm{~J} / \mathrm{g}$. As seen in Figure 15, at the upper segregated part of the alloy sample, lamellar $(\mathrm{Pb})+\mathrm{SbSn}$ eutectics usually form inside the interspaces between divorced 
$(\mathrm{Pb})+\mathrm{SbSn}$ eutectic colonies. In contrast, $(\mathrm{Pb})+\mathrm{SbSn}$ eutectics frequently grow in a radiative way from the edge of $\mathrm{SbSn}$ phase at the lower part of the alloy sample. The $(\mathrm{Pb})+\mathrm{SbSn}$ eutectic microstructures occupy a large volume fraction and display various kinds of interesting morphologies.

(1) Morphology of solidified microstructures. Figure 18 presents various morphologies of $(\mathrm{Pb})+\mathrm{SbSn}$ eutectics at different locations of a $\mathrm{Pb}-14 \% \mathrm{Sb}-10 \% \mathrm{Sn}$ ternary alloy sample undercooled by $68 \mathrm{~K}$. The bright phase is $\mathrm{SbSn}$ intermetallic compound, and the dark phase is $(\mathrm{Pb})$ solid solution. At the upper part of this segregated sample, there are two different kinds of $(\mathrm{Pb})+\mathrm{SbSn}$ eutectics: divorced eutectic and lamellar eutectic, which proceed in different growth temperatures. When alloy temperature drops to $514 \mathrm{~K},(\mathrm{~Pb})$ dendrites precipitate from the liquid phase surrounding primary $\mathrm{SbSn}$ dendrites and blocks, resulting in the formation of divorced $(\mathrm{Pb})+\mathrm{SbSn}$ eutectic structures. At temperatures below $513 \mathrm{~K}$, a large quantity of lamellar $(\mathrm{Pb})+\mathrm{SbSn}$ eutectics form within the interspaces of divorced eutectic colonies. Figure 18(a) is a labyrinth-like eutectic structure formed by the alternating nucleation and coupled growth of $(\mathrm{Pb})$ and $\mathrm{SbSn}$ phases. Figure 18(b) shows a two-phase dendritic morphology of $(\mathrm{Pb})+\mathrm{SbSn}$ eutectics. Regular lamellar eutectics grow from the tips of this sort of two-phase composite dendrites. There are also lots of feather-like $(\mathrm{Pb})+\mathrm{SbSn}$ eutectics originating from the primary $\mathrm{SbSn}$ phase in these composite dendrites. At the lower part of the alloy sample, the $(\mathrm{Pb})+\mathrm{SbSn}$ eutectic colonies frequently take the shape of triangular stars. Lamellar $(\mathrm{Pb})+\mathrm{SbSn}$ structures originate from the primary axes of triangular $\mathrm{SbSn}$ phase and grow in radiative directions. As demonstrated in Figure 18(c), many triangular stars of
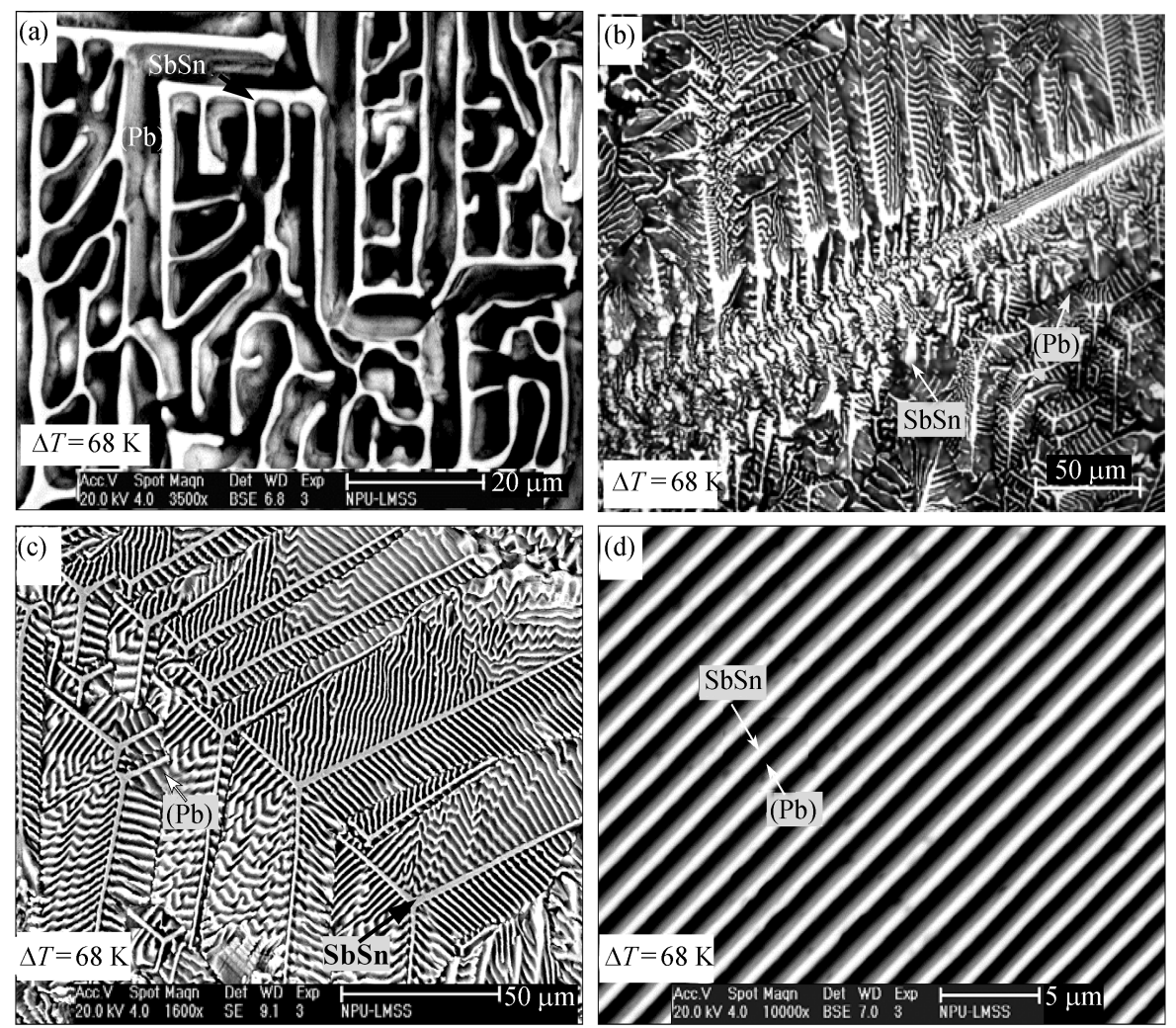

Figure 18 Structural morphology of $(\mathrm{Pb}+\mathrm{SbSn})$ pseudobinary eutectic. (a) Labyrinth-like structure; (b) dendritic morphology; (c) fishbone shaped structure; (d) lamellar structure. 
$(\mathrm{Pb})+\mathrm{SbSn}$ eutectics are so connected that they produce a kind of fishbone-like microstructure. Figure 18(d) gives the regular lamellar eutectics which form at the tails of those triangular stars mentioned above.

(2) Lamellar spacing and solute distribution. Figure 19 presents the interlamellar spacing of $(\mathrm{Pb})+\mathrm{SbSn}$ eutectics versus undercooling at upper and lower parts of undercooled $\mathrm{Pb}-14 \% \mathrm{Sb}-10 \% \mathrm{Sn}$ ternary alloy samples. At small undercooling of $12 \mathrm{~K}$, serious macrosegregation and coarse $\mathrm{SbSn}$ dendrites are formed. In such a case, $(\mathrm{Pb})+\mathrm{SbSn}$ eutectics grow slowly and exhibit large interlamellar spacings. The eutectic growth velocity increases with undercooling, which results in reduced interlamellar spacings and refined microstructures. This structural refinement effect is quite conspicuous during the rapid solidification of undercooled $\mathrm{Pb}-14 \% \mathrm{Sb}-10 \% \mathrm{Sn}$ ternary alloy.

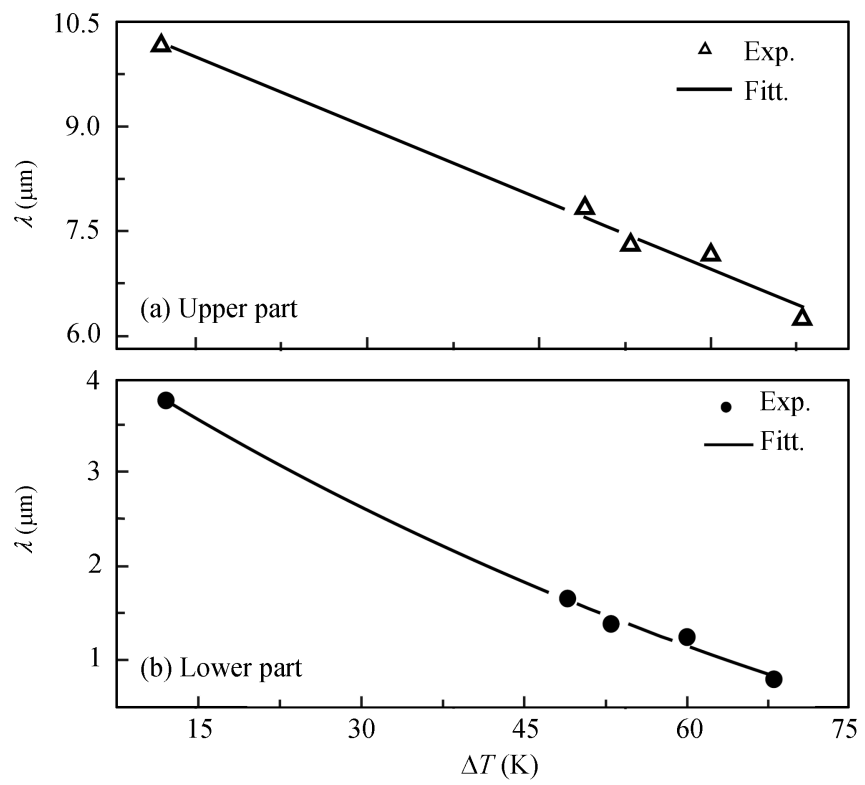

Figure 19 Interlamellar spacing of $(\mathrm{Pb}+\mathrm{SbSn})$ pseudobinary eutectic versus undercooling

EDS scan analyses are conducted to explore the solute distribution profiles of $(\mathrm{Pb})+\mathrm{SbSn}$ eutectics in $\mathrm{Pb}-14 \% \mathrm{Sb}-10 \% \mathrm{Sn}$ ternary alloy. As seen in Figure 20, the white phase is SbSn intermetallic compound, and the dark phase is $(\mathrm{Pb})$ solid solution. The lamellar structures result from the alternating and cooperative growth of $\mathrm{SbSn}$ and $(\mathrm{Pb})$ phases. Figure 20(b) presents the $\mathrm{Sb}$ distribution profile, while Figure 20(c) gives the distribution curve of Sn content.

(v) Growth of ternary eutectics. In the light of DSC curves in Figure $14(\mathrm{a}),(\mathrm{Pb})+(\mathrm{Sb})+\mathrm{SbSn}$ ternary eutectics start to form when alloy temperature decreases to $509 \mathrm{~K}$ and alloy composition attains the ternary eutectic point. It is found by metallographic analyses that ternary eutectic microstructures only appear at the lower part of the alloy sample and exist in the interspaces between $(\mathrm{Pb})+\mathrm{SbSn}$ eutectic colonies. The ternary eutectics occupy only a small volume fraction, which agrees well with the fact that the fourth exothermic peak of Figure 14(a) is very weak.

The microstructure of $(\mathrm{Pb})+(\mathrm{Sb})+\mathrm{SbSn}$ ternary eutectic is illustrated in Figure 15(c), where the white phase is $\mathrm{SbSn}$ phase, the black one is $(\mathrm{Pb})$ phase and the grey one is $(\mathrm{Sb})$ phase. It can be seen that the microstructures consist mainly of $(\mathrm{Pb})$ and $\mathrm{SbSn}$ phases. ( $\mathrm{Sb})$ phase nucleates and grows depending on SbSn phase. When the remnant liquid achieves the temperature and compo- 

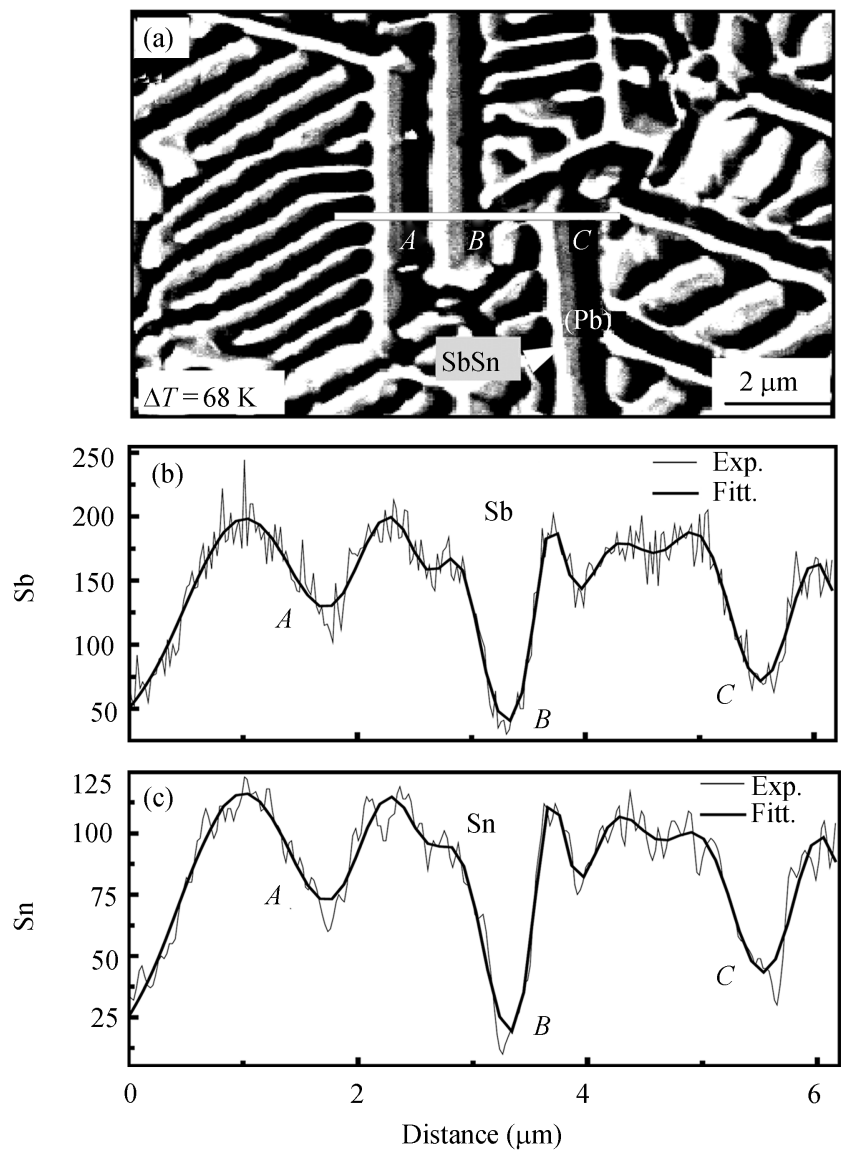

Figure 20 Solute distribution of $(\mathrm{Pb}+\mathrm{SbSn})$ pseudobinary eutectic. (a) EDS scanning line; (b) Sb distribution; (c) Sn distribution.

sition of the ternary eutectic point, the three eutectic phases grow cooperatively and form the anomalous $(\mathrm{Pb})+(\mathrm{Sb})+\mathrm{SbSn}$ ternary eutectic.

(vi) Nucleation characteristics and solidification route. From the DSC curve of Figure 14(a), it is known that the temperature interval between the first and second exothermic peaks is $11 \mathrm{~K}$. In solidification microstructures, $(\mathrm{Pb})+\mathrm{SbSn}$ pseudobinary eutecitcs grow radiatively from the primary $\mathrm{SbSn}$ faceted phase. This shows that $\mathrm{SbSn}$ phase is the effective nucleants for $(\mathrm{Pb})$ and $(\mathrm{Sb})$ phases. Since $(\mathrm{Pb})$ and $\mathrm{SbSn}$ phases have strong mutual affinity, they tend to grow cooperatively and produce various kinds of pseudobinary eutectics. $(\mathrm{Pb})+(\mathrm{Sb})+\mathrm{SbSn}$ ternary eutectic structures exist inside the interspaces of $(\mathrm{Pb})+\mathrm{SbSn}$ eutectic colonies. Although $(\mathrm{Sb})$ and $\mathrm{SbSn}$ phases display dependent growth in ternary eutectic structures, they have never formed $(\mathrm{Sb})+\mathrm{SbSn}$ pseudobinary eutectics independently.

The solidification route of $\mathrm{Pb}-14 \% \mathrm{Sb}-10 \% \mathrm{Sn}$ ternary alloy is shown in Figure 1(a). In the solidification process, primary SbSn phase precipitates from liquid phase at first, when temperature decreases to $525 \mathrm{~K}$. The alloy composition and temperature vary along line $C c$. When temperature falls to $514 \mathrm{~K}$ and $(\mathrm{Pb})+\mathrm{SbSn}$ eutectic line is attained, $(\mathrm{Pb})$ phase nucleates around the $\mathrm{SbSn}$ phase and forms the divorced eutectic microstructure. With the further decrease of temperature to $513 \mathrm{~K}$, a large amount of $(\mathrm{Pb})+\mathrm{SbSn}$ lamellar eutectics are produced. Later on, the alloy composition 
moves ahead along line $c E$. Once alloy temperature drops to the ternary eutectic point $E$, all the remnant liquid is solidified into the $(\mathrm{Pb})+(\mathrm{Sb})+\mathrm{SbSn}$ ternary eutectic microstructure.

\section{Conclusions}

(i) Three types of $\mathrm{Pb}-\mathrm{Sb}$-Sn ternary alloys selected from different primary phase regions have been investigated by undercooling experiments. The primary $(\mathrm{Pb})$ and $\mathrm{SbSn}$ phases grow mainly in a dendritic way, whereas primary $(\mathrm{Sb})$ phase usually displays faceted growth in the form of polygonal blocks and long strips. In the various solidification microstructures, primary $\mathrm{SbSn}$ phase frequently produces serious macrosegregation, while primary $(\mathrm{Pb})$ and $(\mathrm{Sb})$ phases are distributed homogeneously. All of the three primary $(\mathrm{Pb}),(\mathrm{Sb})$ and $\mathrm{SbSn}$ phases are subject to solute trapping effect during rapid solidification, resulting in the remarkable extension of solute solubility under the substantial undercooling condition.

(ii) It is found that $(\mathrm{Pb})$ and $\mathrm{SbSn}$ phases possess strong mutual affinity and produce various kinds of $(\mathrm{Pb})+\mathrm{SbSn}$ pseudobinary eutectics. $(\mathrm{Pb})$ and $(\mathrm{Sb})$ phases nucleate independently and show a weak cooperative growth tendency, which can only lead to divorced pseudobinary eutectics. Although $(\mathrm{Sb})$ and $\mathrm{SbSn}$ phases have not formed pseudobinary eutectics independently, they exhibit dependent growth within $(\mathrm{Pb})+(\mathrm{Sb})+\mathrm{SbSn}$ ternary eutectic structures.

(iii) $\mathrm{The}(\mathrm{Pb})+(\mathrm{Sb})+\mathrm{SbSn}$ ternary eutectic microstructure displays lamellar growth when the alloy composition ensures a large volume fraction for this ternary eutectic. If its volume fraction is small, the ternary eutectic appears as anomalous eutectic. Usually $(\mathrm{Pb})$ and $\mathrm{SbSn}$ phases are the major constitution of ternary eutectic, and $(\mathrm{Sb})$ phase composes only a minor part.

(iv) Microstructural analyses indicate that $(\mathrm{Pb})$ phase is not an efficient heterogeneous nucleant for $(\mathrm{Sb})$ and $\mathrm{SbSn}$ phases. Similarly, $(\mathrm{Sb})$ phase is not a good nucleant for either $(\mathrm{Pb})$ or $\mathrm{SbSn}$ phase. Nevertheless, the SbSn intermetallic compound has acted as the effective nucleant for both $(\mathrm{Pb})$ and $(\mathrm{Sb})$ phases.

(v) The solidification routes of three different types of $\mathrm{Pb}$-Sb-Sn ternary alloys have been determined under the substantial undercooling condition, which is schematically presented in Figure 1. For $\mathrm{Pb}-5 \% \mathrm{Sb}-4 \% \mathrm{Sn}$ ternary alloy, its composition and temperature vary along line $A a$ at first. When point $a$ on the $(\mathrm{Pb})+\mathrm{SbSn}$ pseudobinary eutectic line is attained, its solidification proceeds along line $a E$ subsequently. And this solidification process ends up before the ternary eutectic point $E$ is achieved. Similarly, the solidification process of $\mathrm{Pb}-20 \% \mathrm{~b}-4 \% \mathrm{Sn}$ ternary alloy follows the route " $B b \rightarrow b E \rightarrow E$ ", while that of $\mathrm{Pb}-14 \% \mathrm{Sb}-10 \% \mathrm{Sn}$ ternary alloy takes the route " $C c \rightarrow c E \rightarrow E$ ".

The authors thank Ms. L.N. Ren, Dr. X.Y. Lu, Dr. X.R. Liu, and Mr. H.P. Wang for their help during experiments and valuable discussions.

1 Jackson K A, Hunt J D. Lamellar and rod eutectic growth. Trans AIME, 1966, 236: 1129-1134

2 Akamatsu S, Faivre G. Traveling waves, two-phase fingers, and eutectic colonies in thin-sample directional solidification of a ternary eutectic alloy. Phys Rev E, 2000, 61: 3757-3770

3 Löffler J F, Bossuyt S, Peker A, et al. High-temperature centrifugation: A tool for finding eutectic compositions in multicomponent alloys. J Appl Phys, 2002, 81(22): 4159-4161

4 Ingerly D B, Swenson D, Jan C H, et al. Phase equilibria of the Ga-Ni-As ternary system. J Appl Phys, 1996, 80: 543-550

5 Himemiya T, Umeda T. Three-phase planar eutectic growth models for a ternary eutectic system. Mater Trans JIM, 1999, 40(7): $665-674$

6 Souza S A, Rios C T, Coelho A A, et al. Growth and morphological characterization of Al-Cr-Nb eutectic alloys. J Alloys 
Compds, 2005, 402: 156-161

7 Witusiewicz V T, Sturz L, Rex S. Phase equilibria and eutectic growth in ternary organic system (D) camphor-neopentylglycol-succinonitrile. J Cryst Growth, 2006, 286: 431-439

8 Wilde J D, Froyen L, Witusiewicz V T, Hecht U. Two-phase planar and regular lamellar coupled growth along the univariant eutectic reaction in ternary alloys: An analytical approach and application to the Al-Cu-Ag system. J Appl Phys, 2005, 97 : 113515

9 Anestiev L, Froyen L. Eutectic growth: A closed problem for the solution of the steady-state growth of lamellar eutectics. J Appl Phys, 2002, 92(2): 812-819

10 Wang N, Wei B. Rapid solidification behaviour of Ag-Cu-Ge ternary eutectic alloy. Mater Sci Eng, 2001, 307: 80-90

11 Ruan Y, Cao C D, Wei B B. Rapid growth of ternary eutectics under deep undercooling. Sci China Ser G-Phys Mech Astron, 2004, 47(6): 717-728

12 Matthew J M K. Macrosegregation development during solidification of a multicomponent alloy with free-floating solid particles. Appl Math Model, 2004, 28: 95-107

13 Osamura K. The Pb-Sb-Sn system. Bull Alloy Phase Diagrams, 1985, 6: 372-379

14 Hilger J P. Hardening process in ternary lead-antimony-tin alloys for battery grids. J Power Sources, 1995, 53: 45-51

15 Matthew J M K, Frank P I. Solidification of ternary metal alloys (II): Predictions of convective phenomena and solidification behavior in Pb-Sb-Sn alloys. Int J Heat Mass Transfer, 1997, 40(16): 3837-3847 